\title{
Weight Status at Postpartum: Being Normal Weight Yet Centrally Obese!
}

\author{
Rebecca Cherono $^{1 *}$, Irene A. Ogada ${ }^{2}$, Judith Kimiywe ${ }^{1}$ \\ ${ }^{1}$ Department of Food, Nutrition and Dietetics, Kenyatta University, Nairobi, Kenya \\ ${ }^{2}$ Department of Human Nutrition, St. Francis Xavier University, Antigonish, Canada \\ Email: ^beckycherono5@gmail.com
}

How to cite this paper: Cherono, R., Ogada, I.A. and Kimiywe, J. (2019) Weight Status at Postpartum: Being Normal Weight Yet Centrally Obese! Food and Nutrition Sciences, 10, 1085-1095.

https://doi.org/10.4236/fns.2019.109078

Received: July 22, 2019

Accepted: September 6, 2019

Published: September 9, 2019

Copyright () 2019 by author(s) and Scientific Research Publishing Inc. This work is licensed under the Creative Commons Attribution International License (CC BY 4.0).

http://creativecommons.org/licenses/by/4.0/

(c) (i) Open Access

\begin{abstract}
Background: Obesity among women of child-bearing age has been a public health concern in the recent past. Central obesity has been found to be rising in different countries. Objectives: This study determined prevalence and correlates of central obesity and normal weight central obesity among postpartum women. Study Design: Randomly selected 460 postpartum women attending health facilities for vaccination/growth monitoring of their infants in Kasarani sub-county, Nairobi County, Kenya took part in the study. BMI was used to measure overall obesity. Central obesity was assessed by waist circumference (WC), waist to hips ratio (WHR) and waist to height ratio (WHTR). National Institute of Health and Clinical Excellence (NICE) BMIWC index was used to assess health risk. Bivariate analysis was used to determine correlates of central obesity. Results: The prevalence of $\mathrm{CO}$ as defined by WC, WHR and WHTR were $66.3 \%, 62.1 \%$ and $50.6 \%$ respectively. Prevalence of normal weight central obesity was $39.2 \%, 36.5 \%$, and $34.4 \%$ by WC, WHR, and WHTR respectively. One in every three participants, $38.6 \%$, had high or very high health risk while $15 \%$ had increased risk and $44.1 \%$ had no increased health risk. Parity and age showed significant positive association with central obesity (Age: WC $\mathrm{r}=0.156, \mathrm{p} \leq 0.001$; WHTR $\mathrm{r}=0.190, \mathrm{p} \leq$ 0.001; Parity: WC $r=0.0126, p=0.009$; WHTR $r=0.149, p=0.002)$. Conclusion: Central obesity prevalence was high regardless of the measure used. About a third of the postpartum women with normal weight BMI was centrally obese and was either at high or very high health risk. Health care workers should therefore use a central obesity measure alongside BMI when assessing nutrition status in the study setting.
\end{abstract}

\section{Keywords}

Central Obesity, Overall Obesity, Waist Circumference, Waist Hips Ratio, Waist to Height Ratio 


\section{Introduction}

Obesity among women of child-bearing age has been a concern in the recent past with studies associating it with adverse long term effects on both the mother and child. Globally, between 1980 and 2013, prevalence of obesity among adult women rose from $29.8 \%$ to $38.0 \%$ [1]. In 2013, females above 20 years of age in Eastern Sub-Saharan Africa region were estimated to have had prevalence rates of $23.7 \%$ overweight and $8.8 \%$ obesity and in Kenya, 34.1\% overweight and $15.2 \%$ obesity [1]. Kenya's prevalence of obesity doubled from $6.4 \%$ in 1993 to $15 \%$ in 2014 [2]. Research shows higher rise in obesity prevalence among women than men and in urban than in rural areas of sub-Saharan Africa [3]. Kenyan national prevalence of obesity and overweight among women aged 15 - 49 years rose from $25 \%$ in 2008 to $33 \%$ in 2014 and that of women in Nairobi increased from $41 \%$ in 2008 to $48 \%$ in 2014 , making it the highest in the country [4].

Central obesity measures have been found to predict risk of NCDs when compared with general obesity measures [5] and especially WC in women [6]. Central obesity poses a threat to cardio-metabolic health of individuals independently of overall obesity [7]. Rising trends in central obesity have been found in populations of different countries [8]. A study among Syrian women found central obesity as defined by WC was higher than BMI derived obesity [9]. Some studies have associated high prevalence of central obesity among women with such physiological processes as child bearing [10] [11]. Limited literature is available on central obesity among women in the sub-Saharan Africa region, including Kenya, and more so on postpartum women. Viewed in this context, this study thus determined prevalence and correlates of central obesity and normal weight central obesity among postpartum women attending health facilities in Kasarani sub-county, Nairobi County, Kenya.

\section{Methods}

\subsection{Study Participants and Design}

This study was part of thesis research that investigated dietary practices, body image and nutritional status of postpartum women in Kasarani sub-county, Nairobi County, Kenya. The study used a cross-sectional analytical design with quantitative techniques in collection, analysis and presentation of data. The objectives for this study were to determine the prevalence of central obesity and normal weight central obesity as well as demographic and socio-economic predictors of central obesity among the participants. Women 15 - 49 years of age with infants 6 - 9 months of age, residing in and attending health facilities for vaccination/growth monitoring of their infants within Kasarani Sub-County were included in the study. Mothers who did not give consent or were pregnant were excluded. Data was collected in September and October, 2017.

The sub-county has 2 divisions namely Kasarani and Embakasi North with 11 locations and 24 sub-locations [12]. It has a population of 198,932 of which 99,445 are female [12] and an area of $85.70 \mathrm{~km}^{2}$. A lot of informal trading activi- 
ties take place in Kasarani. Kasarani sub-county was purposively selected because it is heterogeneous, densely populated and has a large number of health centres [13]. The study focused on 50 health facilities that offer vaccination services in the area. The study adopted multistage sampling technique. From lists of health facilities obtained from the vaccine dispatching centre for the sub-county, Dandora 1 health centre, four private health facilities were selected by simple random sampling and six public health facilities were purposively selected since they had large numbers of clients. Proportionate simple random sampling was then used to draw 169 participants from private and 291 from public health facilities. The proportionality was based on attendance in private and public health facilities.

Cochran formula was used to determine the minimum sample size for $95 \%$ confidence interval. It yielded a minimum sample size of 384 . Out of 460 questionnaires administered, data from a total of 433 consenting postpartum women were analysed translating to $94.1 \%$ response rate. Interviews and all measurements were done using structured researcher guided questionnaires at the selected health facilities. The objective of the study was explained to each of the participant and a signed consent obtained before the interview was conducted and anthropometric measurements taken. The researcher sought authority to conduct research from Kenyatta University graduate school and Ethical approval from Kenyatta University Ethical Review Committee before commencing the research. A research permit was sought from National Commission for Science, Technology and Innovation (NACOSTI). The researcher further sought permission from local administration authority and health facilities that were taking part in the study.

\subsection{Study Variables}

The participants were administered a questionnaire that included socio-demographic questions. Demographic characteristics included age, marital status, parity and postpartum time. Socio-economic characteristics included education level, monthly income and occupation category. Level of education was obtained from the participant's self reported highest level attained. During the interview, participant's height, waist and weight measurement were taken.

\subsubsection{Anthropometric Measurement}

The participants' weight was taken in light clothes to the nearest $0.1 \mathrm{~kg}$ in standing position using a SECA electronic digital weighing scale. Height of each participant was taken with participants bare footed and head in the Frankfort plane using SECA 213 wall-mounted stadiometer height rod. Waist measurement was taken by placing tape measure horizontally around participant's waist with the participant standing upright, with minimal clothing at the end of normal exhalation and arms relaxed at the sides. Waist measurement was recorded to the nearest centimetre. Hip circumference was taken by placing the tape measure horizontally around the fullest part of the participant's hips with the participant 
standing upright with minimal clothing and feet placed close together. Hip circumference was recorded to the nearest centimetre. The reliability of all measurements was assessed and adjusted during training and pretesting of questionnaire. All measurements were taken by trained research assistants to ensure uniformity.

\subsubsection{Central Obesity Assessment}

Central obesity (CO) was assessed by use of waist to hip ratio (WHR), waist to height ratio (WHTR) and waist circumference (WC) while overall obesity was assessed by BMI. Waist measurement was divided by hip measurement to get waist to hip ratio while WHTR was obtained by dividing waist size by height. Central obesity cut off points were defined by WHO's criteria [5]: $\mathrm{WC} \geq 0.80$; WHR $>0.85$ or WHTR of $\geq 0.5$ [14]. Normal-weight central obesity in this study refers to $\mathrm{CO}$ among mothers categorized as normal weight by BMI. Body weight in kilograms was divided by the square of the height in metres to get BMI [15]. Body Mass Index was categorized into underweight $(<18.50)$, normal weight (18.50 - 24.99), overweight $(25$ - 29.99) and obese $(\geq 30.00)$ based on WHO's classification [5].

\subsubsection{Health Risk Level}

Health risk level was assessed using BMI-WC matrix developed by National Institute of Health and Clinical Excellence (NICE) for managing overweight and Obesity [16]. Based on this matrix, a person is underweight for a BMI of $<18.50$ $\mathrm{kg} / \mathrm{M}^{2}$, healthy weight for a BMI of $18.50-24.99 \mathrm{~kg} / \mathrm{M}^{2}$, overweight for a BMI of $25-29.99 \mathrm{~kg} / \mathrm{M}^{2}$, obese for a BMI of $30-39.9 \mathrm{~kg} / \mathrm{M}^{2}$ and very obese for a BMI of $\geq 40.00$. Waist Circumference was classified as low if it was $<80 \mathrm{~cm}$, high if it was between $80-88 \mathrm{~cm}$ and very high if $>88 \mathrm{~cm}$. Health risk in the BMI-WC composite index are categorized as: no increased risk defined as healthy weight combined with low or high WC and overweight with low WC; increased risk defined as healthy weight with very high WC, overweight with high WC, and obese with low WC; high risk is defined as overweight with very high WC and obese with high WC; very high risk defined as obese with very high WC and very obese with any category of WC.

\subsection{Data Analysis and Presentation}

Statistical Package for Social Sciences (SPSS) version 20 was used for data entry, cleaning and analysis. Descriptive statistics such as means \pm standard deviations (SD) were used to express continuous variables. Frequencies and percentages were used to describe categorical variables. Bivariate analysis was used to determine correlation between central obesity and socio-demographic variables.

\section{Results}

\subsection{Socio-Demographic Characteristics}

The participants had a mean age of $27.07 \pm 5.277$ years (Table 1 ). Majority of 
the participants were married, $82 \%$ (355), and had completed primary school education, $70.4 \%$ (327). The mothers had a mean parity of $1.9 \pm 0.94$; a mean household size of $4 \pm 1.792$ people. About half of the mothers had a monthly household income of less than KSH. 20,000 equivalent to 200 United States dollars (USD), $47.3 \%$ (205). The participants' mean monthly household income was KSH. $32535.80 \pm 26643.4$.

Table 1. Socio-demographic characteristics.

\begin{tabular}{|c|c|c|}
\hline Characteristic & $\mathrm{N}=433$ & Mean $\pm S D$ \\
\hline Age in complete years & $\mathrm{n}(\%)$ & $27.07 \pm 5.277$ \\
\hline $15-19$ & $24(5.5)$ & \\
\hline $20-29$ & $277(64)$ & \\
\hline $30-39$ & $123(28.4)$ & \\
\hline $40-49$ & $9(2.1)$ & \\
\hline \multicolumn{3}{|l|}{ Marital status } \\
\hline Married & $355(82)$ & \\
\hline Single & $64(14.8)$ & \\
\hline Divorced & $9(2.1)$ & \\
\hline Widowed & $5(1.2)$ & \\
\hline Parity & & $1.9 \pm 0.94$ \\
\hline $1-2$ & $334(77.1)$ & \\
\hline $3-4$ & $96(22.1)$ & \\
\hline $5 \&$ more & $3(0.7)$ & \\
\hline Postpartum period in completed months & & $7.58 \pm 1.037$ \\
\hline 6 & $144(33.3)$ & \\
\hline 7 & $67(15.5)$ & \\
\hline 8 & $50(11.5)$ & \\
\hline 9 & $172(39.7)$ & \\
\hline Household size & & $4 \pm 1.792$ \\
\hline$<3$ & $19(4.4)$ & \\
\hline $3-4$ & $291(67.2)$ & \\
\hline$\geq 5$ & $108(24.9)$ & \\
\hline \multicolumn{3}{|l|}{ Formal education completed } \\
\hline None & $12(2.8)$ & \\
\hline Primary & $327(70.4)$ & \\
\hline Secondary & $27(6.2)$ & \\
\hline Post-primary & $163(37.6)$ & \\
\hline College & $82(18.9)$ & \\
\hline University & $33(7.6)$ & \\
\hline Monthly income (KSH) & & $32,535.80 \pm 26,643.4$ \\
\hline$<20,000$ & $205(47.3)$ & \\
\hline $20,000-50,000$ & $174(40.2)$ & \\
\hline $50,001-100,000$ & $39(9)$ & \\
\hline $100,001-150,000$ & $13(3)$ & \\
\hline$>150,000$ & $2(0.3)$ & \\
\hline
\end{tabular}




\subsection{Prevalence of BMI Derived Obesity and Central Obesity}

The prevalence of underweight, normal, overweight and obese was $2.3 \%, 43.7 \%$, $32.3 \%$ and $21.7 \%$ respectively (Table 2 ). The prevalence of central obesity as defined by WC, WHR and WHTR were $66.3 \%, 62.1 \%$ and $50.6 \%$ respectively.

\subsection{Prevalence of Normal Weight Central Obesity}

Of 189 mothers classified as having normal BMI, the prevalence of central obesity was $39.2 \%$ (74), 36.5\% (69), and $34.4 \%$ (65) by WC, WHR, and WHTR respectively (Figure 1).

\subsection{WC across BMI Categories}

Among healthy weight participants, $39.1 \%$ had high risk or very high risk WC (Table 3). In the overweight category, only $14.3 \%$ had low risk WC while majority of the obese and very obese mothers had very high risk WC.

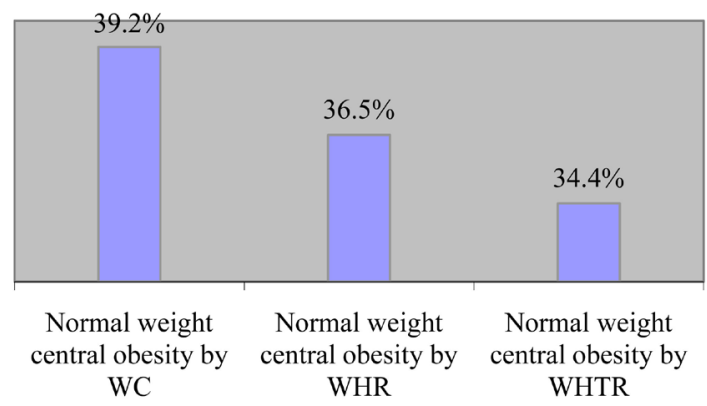

Figure 1. Prevalence of normal weight central obesity using different anthropometric measures.

Table 2. Anthropometric measures.

\begin{tabular}{ccc}
\hline Tool & $\mathrm{N} 433$ & Mean \pm SD \\
\cline { 2 - 3 } BMI & $\mathrm{n}(\%)$ & $26.29 \pm 5.06$ \\
Underweight & $10(2.3)$ & \\
Normal & $189(43.7)$ & \\
Overweight & $140(32.3)$ & \\
Obese & $94(21.7)$ & \\
WC $(>0.80)$ & & \\
Centrally obese & $287(66.3)$ & $0.86 \pm 0.082$ \\
Not centrally obese & $146(33.7)$ & \\
WTHR $(>0.5)$ & & \\
Centrally obese & $269(37.9)$ & \\
Not centrally obese & $164(62.1)$ & \\
WHR $(>0.85)$ & & \\
Centrally obese & $219(50.6)$ & \\
Not centrally obese & $214(49.4)$ & \\
\hline
\end{tabular}


Table 3. WC across BMI categories.

\begin{tabular}{cccc}
\hline \multirow{2}{*}{ BMI categories } & Low risk WC & High risk WC & Very risk $\mathrm{WC}^{+}$ \\
\cline { 2 - 4 } & $\mathrm{n}(\%)$ & $\mathrm{n}(\%)$ & $\mathrm{n}(\%)$ \\
\hline Underweight & $10(100)$ & $0(0)$ & $0(0)$ \\
Healthy weight & $115(60.8)$ & $56(29.6)$ & $18(9.5)$ \\
Overweight & $20(14.3)$ & $45(32.1)$ & $75(53.6)$ \\
Obese & $2(2.2)$ & $7(7.9)$ & $80(89.9)$ \\
Very obese & $0(0)$ & $1(20)$ & $4(80)$ \\
\hline
\end{tabular}

WC waist circumference; $\mathrm{WC}^{*}<80 \mathrm{~cm}, \mathrm{WC}^{\sharp} 80-88 \mathrm{~cm}, \mathrm{WC}^{+}>88 \mathrm{~cm}$.

\subsection{Prevalence of Health Risk}

Based on NICE BMI-WC composite index, more than a third, 38.6\% (167), of the participants had either high or very high health risk while $15 \%$ (65) had increased risk and $44.1 \%$ (191) had no increased health risk.

\subsection{Relationship between Central Obesity and Selected Demographic and Socio-Economic Factors}

Bivariate analysis was used to assess association of central obesity with age, parity, postpartum (PP) time, education level. Age and parity showed significant positive association with central obesity as determined by WC and WHTR ( $p$ > 0.05). Only age showed significant association with CO determined by WHR. There was no significant relationship between educational level as well as postpartum time with central obesity (Table 4).

\section{Discussion}

There is limited literature on central obesity among postpartum women. Most studies reviewed reported on general population with varying definitions for central obesity. Despite these, the prevalence of CO found in this study (66.3\%) is high. Compared to other studies among women, prevalence of $\mathrm{CO}$ in this study as defined by WC is higher than $53.8 \%$ found in Nigeria [17], $47.1 \%$ among Saudi women [18], 51.7\% national prevalence of Chinese women [8], $57.7 \%$ among Lome women in Togo [19]. The prevalence in this study is comparable to the finding of an earlier study among Nairobi women in Kibera that found CO prevalence at $67.5 \%$ [20]. This finding reinforces the postulation that Nairobi women are in the forefront in obesity prevalence in Kenya.

Since Nairobi women have been found with higher obesity rates compared to women of other regions in Kenya [4], it is possible that lifestyle behaviours may be responsible. Factors such as nutrition transition characterized by accelerated change in the structure of diet [21] and body image that appreciates big body [22] may perpetuate obesity rate. Considering the adverse effects of central obesity, there is urgent need to put in place strategies to curb it. 
Table 4. Relationship between CO and selected socio-demographic factors.

\begin{tabular}{ccccccc}
\hline \multirow{2}{*}{ Variable } & \multicolumn{2}{c}{ WC } & \multicolumn{2}{c}{ WHTR } & \multicolumn{2}{c}{ WHR } \\
\cline { 2 - 7 } & $\begin{array}{c}\text { Pearson } \\
\text { correlation }\end{array}$ & P value & $\begin{array}{c}\text { Pearson } \\
\text { correlation }\end{array}$ & P value & $\begin{array}{c}\text { Pearson } \\
\text { correlation }\end{array}$ & P value \\
\hline Age & $0.156^{* *}$ & $<0.001$ & $0.190^{* *}$ & $<0.001$ & $0.144^{* *}$ & 0.003 \\
Parity & $0.0126^{* *}$ & 0.009 & $0.149^{* *}$ & 0.002 & 0.085 & 0.078 \\
PP time & 0.083 & 0.083 & 0.086 & 0.072 & 0.027 & 0.579 \\
Education & 0.003 & 0.945 & -0.018 & 0.713 & 0.049 & 0.307 \\
Income & 0.041 & 0.393 & 0.047 & 0.448 & 0.079 & 0.101 \\
\hline
\end{tabular}

${ }^{*}$ Correlation is significant at 0.01 level ( 2 tailed).

The prevalence of normal weight central obesity in this study of $34.4 \%-39.2 \%$ depending on the criteria used, is higher than $15.4 \%$ reported among Thai health workers [23] and 26.9\% - 36.9\% among South African adults [24]. Persons with normal weight and central obesity have been found with higher mortality risk than with similar BMI but no central obesity [25]. The high prevalence of normal weight central obesity observed in this study is suggestive of the need to include central obesity measures alongside BMI in both preventive and management clinical care practice for NCDs. Use of BMI alone may not capture all at risk individuals [7] [25]. Besides physical activity level and dietary habits, gestational weight retention has been associated with obesity among postpartum women [26]. More than a third of the participants had either high or very high health risk based on NICE BMI-WC composite index. This calls for follow-up programs for mothers after delivery by the Kenyan health ministry as part of strategy to curb rising obesity and the associated health risks.

This study found significant positive association between $\mathrm{CO}$ and age as well as parity. This finding is consistent with findings from other earlier studies [9] [11] [24]. Transient insulin resistance during pregnancy that encourage intraabdominal fat accumulation may explain higher central obesity in women with higher parity [27]. Further, if this gestational weight is not lost, retention may contribute to abdominal obesity.

\section{Strength and Weakness}

To the best knowledge of the authors, this is the first study reporting on central obesity and normal weight central obesity among postpartum Nairobi women. Findings from this study can be useful in guiding clinical practice and follow up programs for postpartum women. The study having been conducted only in Kasarani sub-county may not be representative of the entire Nairobi County. Even so, the results from this study give a hint on the burden of normal-weight central obesity and health risk level of the study population.

\section{Conclusion}

Central obesity prevalence was high regardless of the measure used. A third of 
postpartum women classified by BMI to be normal weight was centrally obese and was either at high or very high health risk. Health care workers should therefore use a central obesity measure alongside BMI when assessing nutrition status in the study setting.

\section{Conflicts of Interest}

The authors declare no conflicts of interest.

\section{References}

[1] Ng, M., Fleming, T., Robinson, M., Thomson, B., Graetz, N., Margono, C., Mullany, E.C., Biryukov, S., Abbafati, C., Abera, S.F., Abraham, J.P., Abu-Rmeileh, N.M.E., Achoki, T., Al Buhairan, F.S., Alemu, Z.A., Alfonso, R., Ali, M.K., Ali, R., Guzman, N.A., Ammar, W., Anwari, P., Banerjee, A., Barquera, S., Basu, S., Bennett, D.A., Bhutta, Z., Blore, J., Cabral, N., Nonato, I.C., Chang, J.-C., Chowdhury, R., Courville, K.J., Criqui, M.H., Cundiff, D.K., Dabhadkar, K.C., Dandona, L., Davis, A., Dayama, A., Dharmaratne, S.D., Ding, E.L., Durrani, A.M., Esteghamati, A., Farzadfar, F., Fay, D.F.J., Feigin, V.L., Flaxman, A., Forouzanfar, M.H., Goto, A., Green, M.A., Gupta, R., Hafezi-Nejad, N., Hankey, G.J., Harewood, H.C., Havmoeller, R., Hay, S., Hernandez, L., Husseini, A., Idrisov, B.T., Ikeda, N., Islami, F., Jahangir, E., Jassal, S.K., Jee, S.H., Jeffreys, M., Jonas, J.B., Kabagambe, E.K., Khalifa, S.E.A.H., Kengne, A.P., Khader, Y.S., Khang, Y.-H., Kim, D., Kimokoti, R.W., Kinge, J.M., Kokubo, Y., Kosen, S., Kwan, G., Lai, T., Leinsalu, M., Li, Y., Liang, X., Liu, S., Logroscino, G., Lotufo, P.A., Lu, Y., Ma, J., Mainoo, N.K., Mensah, G.A., Merriman, T.R., Mokdad, A.H., Moschandreas, J., Naghavi, M., Naheed, A., Nand, D., Narayan, K.M.V., Nelson, E.L., Neuhouser, M.L., Nisar, M.I., Ohkubo, T., Oti, S.O., Pedroza, A., Prabhakaran, D., Roy, N., Sampson, U., Seo, H., Sepanlou, S.G., Shibuya, K., Shiri, R., Shiue, I., Singh, G.M., Singh, J.A., Skirbekk, V., Stapelberg, N.J.C., Sturua, L., Sykes, B.L., Tobias, M., Tran, B.X., Trasande, L., Toyoshima, H., van de Vijver, S., Vasankari, T.J., Veerman, J.L., Velasquez-Melendez, G., Vlassov, V.V., Vollset, S.E., Vos, T., Wang, C., Wang, X., Weiderpass, E., Werdecker, A., Wright, J.L., Yang, Y.C., Yatsuya, H., Yoon, J., Yoon, S.-J., Zhao, Y., Zhou, M., Zhu, S., Lopez, A.D., Murray, C.J.L. and Gakidou, E. (2016) Global, Regional, and National Prevalence of Overweight and Obesity in Children and Adults during 1980-2013: A Systematic Analysis for the Global Burden of Disease Study 2013. The Lancet, 384, 766-781. https://doi.org/10.1016/S0140-6736(14)60460-8

[2] Amugsi, D.A., Dimbuene, Z.T., Mberu, B., Muthuri, S. and Ezeh, A.C. (2017) Prevalence and Time Trends in Overweight and Obesity among Urban Women: An Analysis of Demographic and Health Surveys Data from 24 African Countries, 1991-2014. BMJ Open, 7, e017344. https://doi.org/10.1136/bmjopen-2017-017344

[3] Charles, A., Medisch, A., Universiteit, C., Boatemaa, S. and Frempong, G. (2015) Obesity in Sub-Saharan Africa Obesity in Sub-Saharan Africa.

[4] KNBS and ICF International (2014) 2014 Kenya Demographic and Health Survey. 177.

[5] Goh, L.G.H., Dhaliwal, S.S., Welborn, T.A., Lee, A.H. and Della, P.R. (2014) Anthropometric Measurements of General and Central Obesity and the Prediction of Cardiovascular Disease Risk in Women: A Cross-Sectional Study.

[6] Bembenek, J.P., Karlinski, M., Niewada, M., Kurkowska-Jastrzębska, I. and Członkowska, A. (2018) Measurement of Nutritional Status Using Body Mass Index, Waist-to-Hip Ratio, and Waist Circumference to Predict Treatment Outcome in 
Females and Males with Acute First-Ever Ischemic Stroke. Journal of Stroke and Cerebrovascular Diseases, 27, 132-139.

https://doi.org/10.1016/j.jstrokecerebrovasdis.2017.08.016

[7] Zhang, C., Rexrode, K.M., Van Dam, R.M., Li, T.Y. and Hu, F.B. (2008) Abdominal Obesity and the Risk of All-Cause, Cardiovascular, and Cancer Mortality Sixteen Years of Follow-Up in US Women. Circulation, 117, 1658-1667. https://doi.org/10.1161/CIRCULATIONAHA.107.739714

[8] Du, P., Wang, H., Zhang, B., Qi, S., Mi, Y., Liu, D. and Tian, Q. (2017) Prevalence of Abdominal Obesity among Chinese Adults in 2011. Journal of Epidemiology, 27, 282-286. https://doi.org/10.1016/j.je.2017.03.001

[9] Bakir, M.A., Hammad, K. and Mohammad, L. (2017) Prevalence of Obesity, Central Obesity, and Associated Socio-Demographic Variables in Syrian Women Using Different Anthropometric Indicators. Anthropological Review, 80, 191-205. https://doi.org/10.1515/anre-2017-0013

[10] Gunderson, E.P. (2009) Childbearing and Obesity in Women: Weight before, during, and after Pregnancy. Obstetrics and Gynecology Clinics, 36, 317-332. https://doi.org/10.1016/j.ogc.2009.04.001

[11] Gunderson, E.P., Sternfeld, B., Wellons, M.F., Whitmer, R.A., Chiang, V., Jr., C.P.Q., Lewis, C.E. and Sidney, S. (2008) Childbearing May Increase Visceral Adipose Tissue Independent of Overall Increase in Body Fat. Obesity, 16, 1078-1084. https://doi.org/10.1038/oby.2008.40

[12] Nairobi County Government (2014) Nairobi County Integrated Development Plan. 26-79.

[13] KNBS (2013) Exploring Kenya's Inequality. In: Ali Nadim Zaidi, L.W., Ed., Exploring Kenya’s Inequality, Kenya National Bureau of Statistics, Nairobi, 15-117.

[14] Ashwell, M. and Gibson, S. (2009) Waist to Height Ratio Is a Simple and Effective Obesity Screening Tool for Cardiovascular Risk Factors: Analysis of Data from the British National Diet and Nutrition Survey of Adults Aged 19-64 Years. Obesity Facts, 2, 97-103. https://doi.org/10.1159/000203363

[15] WHO (2014) Noncommunicable Diseases Country Profiles 2014.

[16] N. I. for H. and C. Excellence (2010) NICE CG43 Obesity: Guidance on Prevention, Identification, Assessment and Management of Overweight and Obesity I Adults and Children. 1-84.

[17] Amole, I.O., Odeigah, L.O. and Adesina, S.A. (2011) The Prevalence of Abdominal Obesity and Hypertension amongst Adults in Ogbomoso, Nigeria. African Journal of Primary Health Care \& Family Medicine, 3, 188.

https://doi.org/10.4102/phcfm.v4i1.188

[18] Mm, A. and Jackson, R.T. (2017) Physical Activity and the Prevalence of General and Abdominal Obesity among Saudi Women of Reproductive Age in Jeddah City. Journal of Obesity and Overweight, 3, 1-14. https://doi.org/10.15744/2455-7633.3.104

[19] Damorou, F., Yayehd, K., Ncho Mottoh, M.P., Tcherou, T., Ehlan, E., Nda, N.W. and Randrianarisoa, F. (2013) Prevalence and Determinants of Obesity among Workers in Lomé (Togo). Science Alert, 6, 19-27. https://doi.org/10.3923/rjc.2013.19.27

[20] Mbochi, R.W., Kuria, E., Kimiywe, J., Ochola, S. and Steyn, N.P. (2012) Predictors of Overweight and Obesity in Adult Women in Nairobi Province, Kenya. BMC Public Health, 12, Article No. 823. https://doi.org/10.1186/1471-2458-12-823

[21] Popkin, B.M. (2015) Symposium: Obesity in Developing Countries: Biological and 
Ecological Factors. The Nutrition Transition and Obesity in the Developing World. 1991-1994.

[22] Lynch, E., Liu, K., Wei, G.S., Spring, B., Kiefe, C. and Greenland, P. (2009) The Relation between Body Size Perception and Change in Body Mass Index over 13 Years. American Journal of Epidemiology, 169, 857-866.

https://doi.org/10.1093/aje/kwn412

[23] Thaikruea, L. and Thammasarot, J. (2016) Prevalence of Normal Weight Central Obesity among Thai Healthcare Providers and Their Association with CVD Risk: A Cross-Sectional Study. Scientific Reports, 6, Article No. 37100. https://doi.org/10.1038/srep37100

[24] Owolabi, E.O., Ter Goon, D. and Adeniyi, O.V. (2017) Central Obesity and Normal-Weight Central Obesity among Adults Attending Healthcare Facilities in Buffalo City Metropolitan Municipality, South Africa: A Cross-Sectional Study. Journal of Health, Population and Nutrition, 36, 54.

https://doi.org/10.1186/s41043-017-0133-x

[25] Sahakyan, K.R., Somers, V.K., Rodriguez, J.P., Jensen, M.D., Roger, V.L. and Singh, P. (2016) Normal Weight Central Obesity: Implications for Total and Cardiovascular Mortality. Annals of Internal Medicine, 163, 827-835. https://doi.org/10.7326/M14-2525

[26] Moll, U., Olsson, H. and Landin-olsson, M. (2017) Impact of Pregestational Weight and Weight Gain during Pregnancy on Long-Term Risk for Diseases. PLoS ONE, 12, e0168543. https://doi.org/10.1371/journal.pone.0168543

[27] Ingram, K.H., Hunter, G.R., James, J.F. and Gower, B.A. (2017) Central Fat Accretion and Insulin Sensitivity: Differential Relationships in Parous and Nulliparous Women. International Journal of Obesity, 41, 1214-1217. https://doi.org/10.1038/ijo.2017.104 